\title{
Dynamic performance of a vehicular bridge with lightweight FRP composite structural elements
}

\author{
Tomasz Siwowski ${ }^{1, *}$, Mateusz Rajchel ${ }^{1}$ \\ ${ }^{1}$ Rzeszow University of Technology, Department of Roads \& Bridges, 35-395 Rzeszow, Poland
}

\begin{abstract}
The lightweight nature and low stiffness of fibre reinforced polymer (FRP) structures combined with low material damping may lead to excessive structural vibration and may increase the dynamic amplification of deformations and stresses in FRP bridge structures. The paper provides a short review on dynamic characterization of existing vehicular bridge superstructures made of FRP structural components. Against the backdrop of a worldwide review the paper presents a field study on the dynamic characteristics of the hybrid FRP - concrete bridge superstructure recently built in Poland. The dynamic amplification factor, the first natural frequency and the damping ratio were experimentally determined in static and dynamic load tests and compared with the relevant codes and requirements. The paper concludes by summarizing challenges related to structural dynamics of bridge superstructures with FRP structural components.
\end{abstract}

\section{Introduction}

Since the beginning of the XXI century the fibre reinforced polymer (FRP) composites have become an integral part of the construction industry because of their versatility, high strength-to-weight ratio, enhanced durability, resistance to fatigue and corrosion, accelerated construction as well as lower maintenance and life-cycle costs. Due to these excellent performance characteristics FRP composites offer very promising options for a wide range of civil infrastructure applications, particularly in bridge engineering [1-3].

However, relative low mass, low damping and low stiffness make FRP composite bridges sensitive to dynamic excitation, which may lead to discomfort of human occupants and larger dynamic amplification of stress and deformation than is encountered in structures made of conventional structural materials. Consequently, design might be governed by a vibration serviceability state. Lack of data on vibration performance of FRP structures and non-existence of a state-of-the-art vibration serviceability design guideline means that current practice is conservative, often meaning only short-span FRP bridge solutions are executed. To fully exploit the benefits of using FRP composites and to extend their use beyond current practice requires a better understanding of dynamic behaviour.

The paper provides a short review on dynamic characterization of constructed vehicular bridge superstructures made of FRP structural components as well as the basic

*Corresponding author: siwowski@prz.edu.pl 
characteristics of a novel bridge superstructure with FRP components recently built in Poland. Against the backdrop of a worldwide review the paper presents a field study on the dynamic characteristics of the hybrid FRP - concrete bridge superstructure constructed with FRP box girders and concrete deck slab. The dynamic amplification factor (DAF), the first natural frequency and the damping ratio were experimentally determined in the static and dynamic load tests and compared with the relevant codes and requirements. The paper concludes by summarizing challenges related to structural dynamics of bridge superstructures with FRP structural components.

\section{Review on dynamic characteristics of FRP vehicular bridges}

Among all constructed vehicular bridges using FRP structural elements (normally FRP girders or decks), the dynamic analysis and characterization has been conducted on several cases from published data. A summary of the available information is presented in Table 1, where the dynamic amplification factors, the first natural frequencies and the damping ratios are provided. However, because not all dynamic parameters were determined in the analysed field tests, the considerable lack of data was revealed in this review.

Table 1. Dynamic characteristics of the constructed FRP vehicular bridges.

\begin{tabular}{|c|c|c|c|c|c|c|}
\hline \multirow[b]{2}{*}{ Bridge name } & \multirow[b]{2}{*}{$\begin{array}{l}\text { Structural } \\
\text { system }\end{array}$} & \multirow{2}{*}{$\begin{array}{c}\text { Main } \\
\text { dimensions } \\
\text { L x B } \\
{[\mathrm{m}]}\end{array}$} & \multicolumn{3}{|c|}{ Dynamic characteristics } & \multirow[b]{2}{*}{ Source } \\
\hline & & & DAF & $\begin{array}{c}\text { first } \\
\text { natural } \\
\text { frequency } \\
{[\mathrm{Hz}]}\end{array}$ & $\begin{array}{c}\text { damping } \\
\text { ratio } \\
{[\%]}\end{array}$ & \\
\hline $\begin{array}{c}\text { Tom's Creek } \\
\text { Bridge }\end{array}$ & $\begin{array}{l}\text { FRP girders, } \\
\text { wooden deck }\end{array}$ & $5.33 \times 6.70$ & 1.90 & N/A & N/A & {$[4]$} \\
\hline $\begin{array}{c}\text { Route } 601 \\
\text { Bridge }\end{array}$ & $\begin{array}{l}\text { FRP girders, } \\
\text { glulam deck }\end{array}$ & $11.90 \times 8.54$ & 1.36 & N/A & N/A & {$[5]$} \\
\hline $\begin{array}{l}\text { Laurel Lick } \\
\text { Bridge }\end{array}$ & $\begin{array}{l}\text { FRP girders, } \\
\text { FRP deck }\end{array}$ & $5.79 \times 4.88$ & 1.93 & N/A & N/A & {$[6]$} \\
\hline $\begin{array}{l}\text { Bennetts' } \\
\text { Creek Bridge }\end{array}$ & FRP slab & $7.81 \times 10.14$ & 1.52 & 26.8 & 4.53 & {$[7]$} \\
\hline $\begin{array}{c}\text { Nowa Wies } \\
\text { Bridge }\end{array}$ & $\begin{array}{l}\text { FRP girders, } \\
\text { FRP deck }\end{array}$ & $10.00 \times 7.70$ & 1.10 & 10.1 & 4.5 & {$[8]$} \\
\hline $\begin{array}{l}\text { Toowoomba } \\
\text { Bridge }\end{array}$ & $\begin{array}{l}\text { Hybrid FRP- } \\
\text { concrete } \\
\text { beams }\end{array}$ & $10.0 \times 5.0$ & N/A & 9.5 & 2.0 & [9] \\
\hline $\begin{array}{c}\text { Tides Mill } \\
\text { Stream } \\
\text { Bridge }\end{array}$ & $\begin{array}{l}\text { Hybrid FRP- } \\
\text { concrete } \\
\text { beams }\end{array}$ & $13.50 \times 9.90$ & 1.23 & N/A & N/A & {$[10]$} \\
\hline
\end{tabular}

It is clearly seen from Table 1 that DAF of FRP bridges ranges from 1.10 to 1.93 . The majority of the obtained DAFs exceeded the design values as shown in the relevant national standards (typically in the range of $1.25-1.33$ ). There has been no consensus made on how to implement the DAF in designing FRP bridge superstructures. The first natural frequency ranges from 9.5 to 26.8 and is much higher (means better) than recommended values according to the relevant standards, typically above $3 \mathrm{~Hz}$. However, the damping ratio in 
the range of $2.0-4.53 \%$ is considerably smaller than the corresponding values for concrete bridges, which are typically about $8 \%$.

The experimental results of the studies shown in Table 1 demonstrate that FRP bridge dynamic behaviour has not been completely recognized. Due to small number of existing results and large discrepancies between them, the dynamic characteristics of bridge superstructures consisting of lightweight FRP structural elements should be still investigated and analysed. Moreover, only a very limited number of research studies have been conducted on FRP-concrete hybrid bridges. In addition, a global structural integrity and health condition evaluation is necessary to ensure the long term performance of the key structures made of FRP composites. Evaluating integrity and health condition of FRP bridges through structural dynamic characterization could be a promising technique to be developed. Therefore the acceptance of such FRP bridge designs requires much more field evaluation of their structural performance. The comprehensive testing of the actual FRP concrete superstructure under dynamic loading provides much improved insight and understanding of this unique structural system.

\section{Description of the bridge superstructure}

The hybrid FRP composite - concrete vehicular bridge is situated in southeast part of Poland along a local road [11]. This is a $22.0 \mathrm{~m}$ long single-span simple supported bridge with $10.5 \mathrm{~m}$ wide deck carrying $2 \times 3.5 \mathrm{~m}$ wide roadway and $1 \times 2.0 \mathrm{~m}$ wide sidewalk. Its nominal carrying capacity is 40 tonnes according to the Polish bridge standard. The bridge superstructure is formed by four FRP composite box girders with $0.18 \mathrm{~m}$ thick concrete deck slab acting compositely with the girders (Fig. 1). The deck equipment consists of two concrete sidewalk slabs with safety barriers, polymer curbs, conventional insulation and stone mastic asphalt (SMA) pavement layer, drainage and expansion joints.

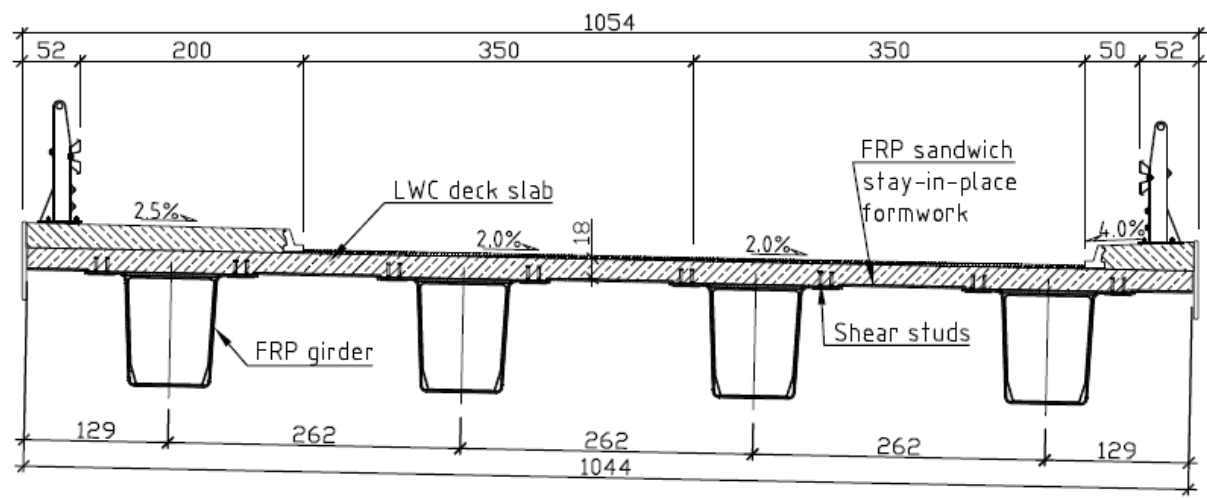

Fig. 1. Cross-section of the FRP composite - concrete bridge superstructure.

Each girder consists of two main parts: a FRP composite box with trapezoid open crosssection and a concrete slab. Steel shear connectors are used to ensure a composite action between FRP composite and concrete. The FRP composite box is $1025 \mathrm{~mm}$ deep, $1550 \mathrm{~mm}$ wide at the top and $621 \mathrm{~mm}$ wide at the bottom. The both top flanges of the shell are 301 $\mathrm{mm}$ wide and are connected with the bottom plate by means of two slightly inclined webs. The individual laminates have the thickness of about $25 \mathrm{~mm}, 22 \mathrm{~mm}$ and $19 \mathrm{~mm}$ for top flanges, webs and bottom plate, respectively. The top flanges and webs are made of solid and sandwich GFRP respectively, whereas the bottom plate has a hybrid GFRP/CFRP solid structure. The sandwich webs consist of $15 \mathrm{~mm}$ thick polyvinyl chloride (PVC) foam core and two $3.5 \mathrm{~mm}$ thick GFRP face laminates. To increase the torsional stiffness of the FRP 
box and to prevent shear-bending buckling of its webs, internal diaphragms are placed along the length of the girder. The diaphragms are made of sandwich panels with the structure similar to webs.

The $180 \mathrm{~mm}$ thick concrete deck slab is made of 35/38 class lightweight concrete (LWC) based on lytag type aggregate and reinforced longitudinally and transversally with two grids of $12 \mathrm{~mm}$ GFRP bars. The LWC slab is connected to FRP box girders by means of shear connectors made of galvanized steel bolts welded to small steel plates and fastened to box top flanges with epoxy adhesive. The $950 \mathrm{~mm}$ long support zones of each girder are filled with LWC to form support end cross-beams and to ensure transverse stiffness of entire superstructure. Steel plates with welded steel bolts are fastened to the webs inside each FRP box to ensure a composite action between FRP composite and concrete in the support zones.

Finite element (FE) structural analysis, design according to new European recommendations as well as construction process of the bridge have been briefly described elsewhere $[11,12]$.

\section{Dynamic testing of the bridge}

Three dynamic tests were performed to measure dynamic characteristics of the superstructure by driving the truck with an approximate total load of $320 \mathrm{kN}$ along the bridge with a speed of 10,30 and $50 \mathrm{~km} / \mathrm{h}$ (schemes D1 to D3, respectively). To increase the dynamic effect two additional tests were also performed: test with speed of $30 \mathrm{~km} / \mathrm{h}$ and sudden braking on the deck in midspan (scheme D4) and test with a speed of $10 \mathrm{~km} / \mathrm{h}$ and the $0.05 \mathrm{~m}$ deep obstacle placed transversally on the deck in midspan (scheme D5).
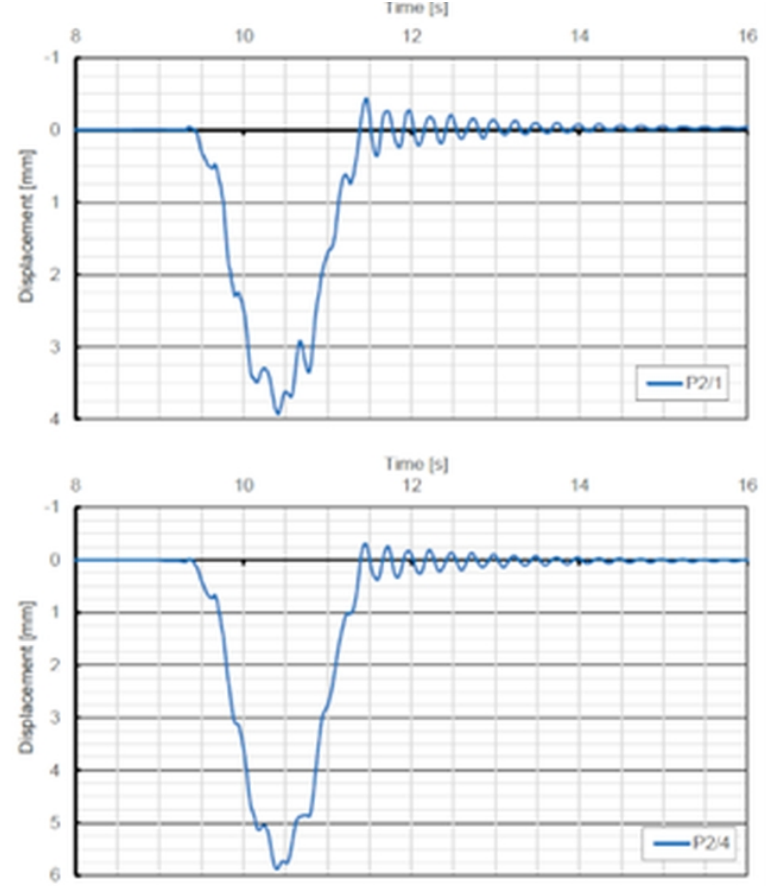

Fig. 2. Dynamic response in the midspan of both external girders under D3 load scheme $(50 \mathrm{~km} / \mathrm{h})$.

During dynamic load tests the displacements and accelerations of the hybrid superstructure were measured at six points: four linear variable differential transducers 
(LVDTs) were mounted to girders in the midspan (measurement points $\mathrm{P} 2 / 1$ to $\mathrm{P} 2 / 4$ for all four girders, respectively) and two piezoelectric accelerometers were attached to deck slab in the midspan. The digital data acquisition system HBM Spider with Quantum X amplifier was used to record all relevant measurements. Dynamic responses in the midspan of both external girders under D3, D4 and D5 load schemes are shown in Figs 2, 3 and 4, respectively.
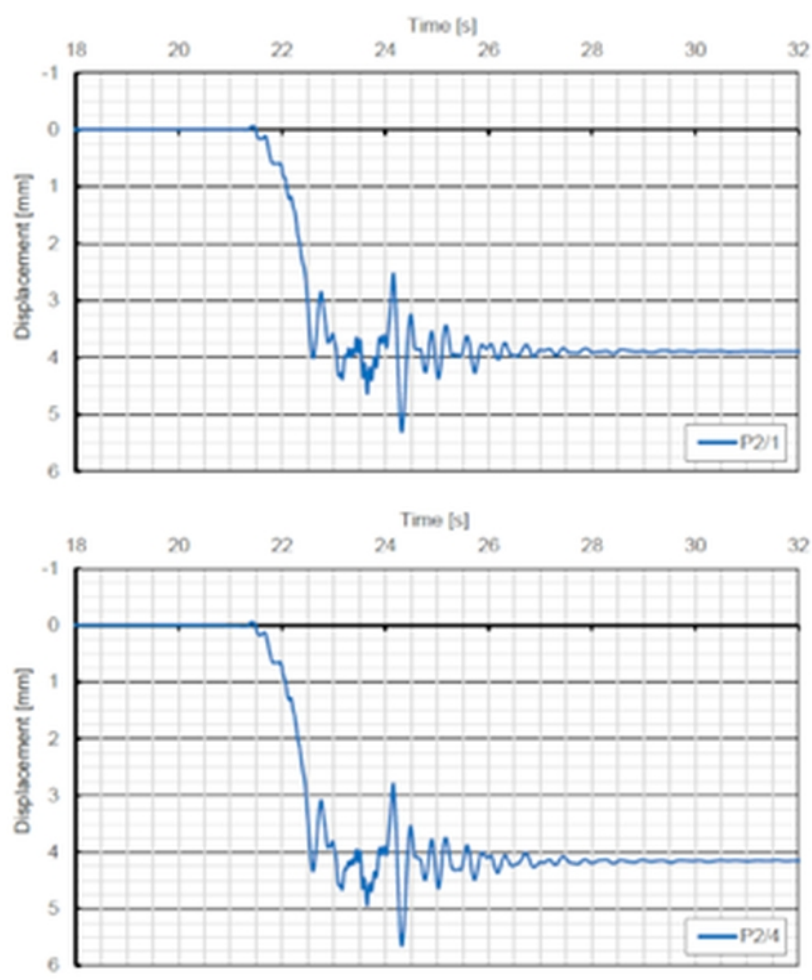

Fig. 3. Dynamic response in the midspan of both external girders under D4 load scheme $(30 \mathrm{~km} / \mathrm{h}+$ braking).

The dynamic amplification factor accounts for the amplification of the design static live load due to a moving vehicle crossing a bridge. This factor is typically described as a function of the interaction of the bridge and vehicle and is influenced by properties such as mass, stiffness, vehicle speed, and surface roughness. The DAF for each load scheme was calculated as the ratio of maximum dynamic displacement (read directly from the "time displacement" plots) and maximum static displacement, measured under the relevant truck positioned in the midspan (static schemes, not reported here). Basing on measured displacements, the DAFs for all vehicle speeds $(10 / 30 / 50 \mathrm{~km} / \mathrm{h})$ were assessed as $1.055 / 1.104 / 1.063$, respectively. All these values are much lower than the DAF used in bridge design (1.25). Moreover, the determined factors are much lower than the average dynamic amplification factor of the similar US hybrid bridge (see Table 1 and [10]) equalled as much as 1.23 in the most heavily loaded girders.

The first natural frequency of the hybrid superstructure was determined by means of the "time-displacement" plot for scheme D5 with the transverse obstacle on the deck slab (Fig. 4 ) as the ratio of number of displacement peaks in time $t_{s}$ and this time $t_{s}$ (in seconds). The estimated first natural frequency of the hybrid superstructure equalled $3.98 \mathrm{~Hz}$ and was higher (means better) than recommended value according to the performance requirements 
for road bridges in Poland (minimum value $3.0 \mathrm{~Hz}$ ). Finally, the experimentally determined logarithmic decrement $\delta$ was determined by means of the "time-displacement" plot for scheme D4 with braking (Fig. 3). The obtained value $\delta=0.201$ was used for estimating span's damping ratio, which relevant value amounts $3.2 \%$. As might be expected this value is much lower than corresponding damping characteristics for a typical concrete bridge with similar beam-slab superstructure and span length.
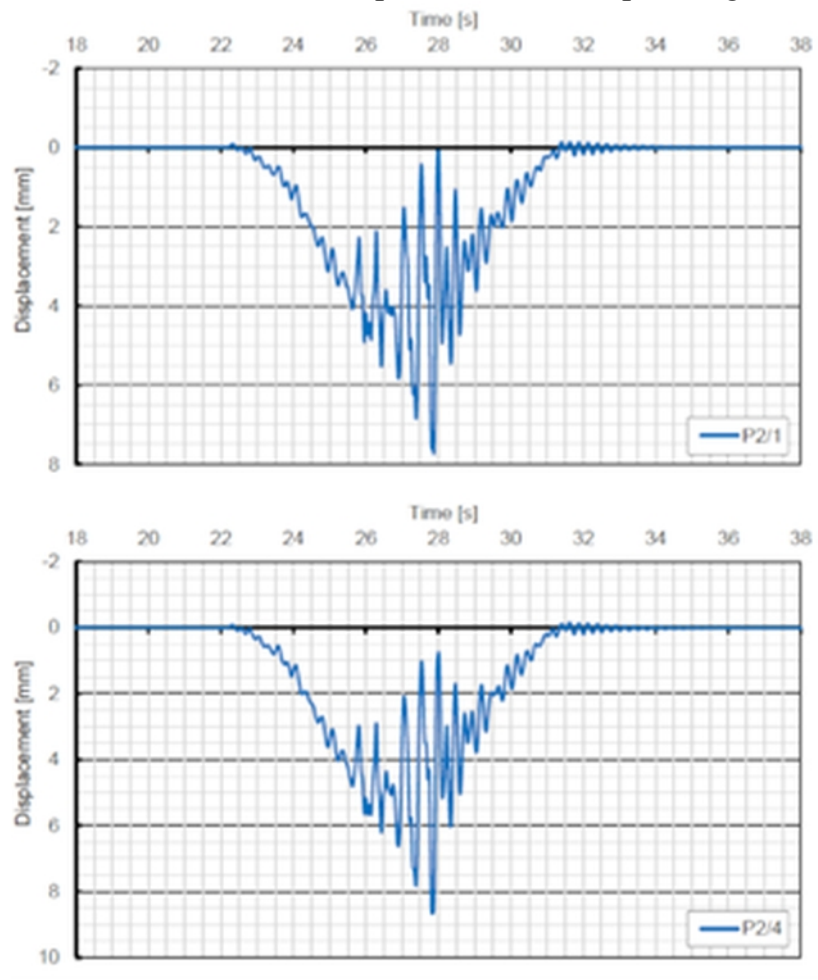

Fig. 4. Dynamic response in the midspan of both external girders under D5 load scheme $(10 \mathrm{~km} / \mathrm{h}+$ transverse obstacle).

\section{Summary and conclusions}

This investigation focused on evaluating the dynamic performance under proof load of a newly constructed hybrid FRP composite - concrete bridge superstructure. The bridge superstructure was instrumented with a series of LVDTs and accelerometers to measure the relevant dynamic characteristics. The dynamic tests were conducted using single truck weighing $320 \mathrm{kN}$ and moving with various speeds. The results obtained from the experimental investigation were used to determine three key dynamic performance characteristics: dynamic amplification factor, first natural frequency and damping ratio.

The main findings of the study are summarized as follows: DAFs for speeds 10/30/50 $\mathrm{km} / \mathrm{h}$ were assessed as 1.055/1.104/1.063, respectively; estimated first natural frequency equalled $3.98 \mathrm{~Hz}$ and experimentally determined logarithmic decrement $\delta=0.201$ enabled to estimate the span's damping ratio as $3.2 \%$. All these parameters revealed very good dynamic behaviour of the hybrid bridge superstructure. Moreover, with respect to the dynamic performance, the novel hybrid system fully conformed to the provisions of the domestic bridge standards and the new European recommendations for FRP bridges [13]. 
To use FRP structures in vehicular bridge, the dynamic characteristics of the bridge superstructure should be carefully examined. The value of the dynamic coefficient has not been well established for FRP bridges. Generally, the analytical and experimental process used for conventional bridges can be applied into FRP bridges. However, attention should be paid to the fact that the isotropic constitutive material modelling of traditional bridge analysis needs to be replaced by orthotropic constitutive material modelling. The finite element (FE) model should be calibrated against the results gathered during field testing of an actual bridge superstructure under dynamic load following the well-established and proved procedure $[14,15]$.

Another challenge is how to improve the damping property of FRP bridge superstructures, although this problem is common in civil engineering, the brittle nature of FRP (especially for GFRP) makes it more critical. Some research has been carried out to improve the material damping properties. A promising alternative is to improve system damping. One of them is to design a hybrid FRP - concrete structure. The dynamic tests conducted to date along with the described above have clearly revealed that hybrid FRP concrete bridges are much better with the respect of dynamic behaviour then their allcomposite counterparts. These results are also encouraging for the design of hybrid bridge systems where the initial cost of the FRP material is a substantial portion of the superstructure cost.

All these challenges necessitate the study of structural dynamics of FRP bridges. A global non-destructive evaluation technique through structural dynamic parameters is an opportunity for dynamic analysis of structural characteristics, which is also useful to ensure the long term performance of FRP bridges [16].

\section{Acknowledgments}

This work was created within the framework of the project: "ComBridge - An innovative FRP composite road bridge". The project was implemented as part of a pilot programme entitled: Support for Research and Development Works in the Demonstrative Scale DEMONSTRATOR+ (Contract No. DEM-1-041/001) and was co-founded by the National Centre for Research and Development, Poland (NCBiR) as well as the industry partners: Mostostal Warszawa S.A. and Promost Consulting, Rzeszow.

\section{References}

1. L. C. Holloway, P. R. Head, Advanced polymer composites and polymers in the civil infrastructure (Elsevier Science Ltd, London, 2001)

2. M. Zoghi (Ed.), The international handbook of FRP composites in civil engineering (CRC Press, Taylor \& Francis Group LLC, Boca Raton, 2014)

3. T. Siwowski, FRP composite bridges. Structural shaping, analysis and testing (Wydawnictwo Naukowe PWN, Warsaw, 2018)

4. W. D. Neely Jr, Evaluation of in-service performance of the Tom's Creek Bridge (Virginia Polytechnic Institute and State University, Blacksburg, VA, 2000)

5. T. E. Cousins, J. J. Lesko, Construction of a Virginia Short-Span Bridge with the Strongwell 36-Inch Double-Web I-Beam - Report No. VTRC 06-CR5 (Virginia Transportation Research Council, Charlottesville, VA, 2005)

6. S. Aluri, C. Jinka, H.V.S. GangaRao, Dynamic response of three fibre reinforced polymer composite bridges, J Bridge Eng 10, 6 (2005) 
7. A. J. Aref, S. Alampalli, Vibration characteristics of a fiber reinforced polymer bridge superstructure, Compos Struct 52, 3-4 (2001)

8. T. Siwowski, M. Rajchel, D. Kaleta, Dynamic characterisation of road bridge made of fibre reinforced polymer composites, J Civ Eng EnvArch XXXIV, 64 (2017)

9. G. M. Van Erp, T. J. Heldt, L. Mc-Cormick, D. Carter, C. Tranberg, Development of an Innovative Fibre Composite Deck Unit Bridge, Proc. IABSE, Melbourne, 2002.

10. D. K. Harris, J. M. Civitillo, A. Gheitasi, Performance and behavior of hybrid omposite beam bridge in Virginia: live load testing, J Bridge Eng 21, 6 (2016)

11. M. Rajchel, T. Siwowski, Research on the hybrid FRP composite - concrete bridge girder, J Civ Eng EnvArch XXXII, 62 (2015)

12. T. Siwowski, D. Kaleta, M. Rajchel, L. Wlasak, The first Polish road bridge made of FRP composites, Struct Eng Int 27, 2 (2017)

13. L. Ascione, E. Gutierez, S. Dimova, A. Pinto, S. Denton, Prospect for new guidance in the design of FRP - Scientific and Technical Report No. 27666 (Joint Research Centre, European Union, Brussels, 2016)

14. J. Chróścielewski, M. Miśkiewicz, Ł. Pyrzowski, M. Rucka, B. Sobczyk, K. Wilde, Modal properties identification of a novel sandwich footbridge - Comparison of measured dynamic response and FEA. Com Part B: Eng 151 (2018)

15. J. Chróścielewski, T. Ferenc, T. Mikulski, M. Miśkiewicz, Ł. Pyrzowski, Numerical modelling and experimental validation of full-scale segment to support design of novel GFRP footbridge, Compos Struct 213 (2019)

16. A. Zhou, Y. Bai, T. Keller, Dynamic characteristics of bridge superstructures with FRP composite structural elements, Proc. CCC, Lyon. (2005) 